
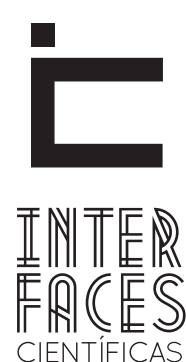

HUMANAS E SOCIAIS

\title{
ASPECTOS POLÍTICOS DA EDUCAÇÃO QUILOMBOLA: CURRÍCULOE PRÁTICA PEDAGÓGICA EM DISCUSSÃO
}

\author{
POLITICAL ASPECTS OF QUILOMBOLA EDUCATION: CURRICULUM AND PEDAGOGICAL PRACTICE IN DISCUSSION \\ ASPECTOS POLIITICOS DE LA EDUCACIÓN QUILOMBOLA: CURRÍCULO Y PRÁCTICA PEDAGÓGICA EN DISCUSIÓN
}

Jaqueline Santana ${ }^{1}$

\section{RESUMO}

Este artigo pretende discutir rumos e caminhos para implementação da Lei 10639/03 e das Diretrizes Curriculares Nacionais para a Educação das Relações Étnicorraciais no âmbito das escolas quilombolas, por meio do entendimento de como a cultura local, ao ser utilizada como recurso pedagógico interdisciplinar, pode contribuir para a construção de identidade das crianças. Para tanto, será realizada uma revisão bibliográfica que tem como pressupostos teóricos, os estudos relativos à educação quilombola e da educação etnicorracial, assim como aqueles referentes ao papel da cultura como instrumento de construção de identidade e conquista de cidadania. Espera-se, com tal discussão, promover reflexões acerca dos quilombos e de sua importância para a sociedade brasileira, assim como fomentar novas possibilidades de trabatho educativo nesses espaços.

\section{PALAVRAS-CHAVE}

Educação Quilombola. Currículo. Metodologias Interdisciplinares. 


\section{ABSTRACT}

This article discusses directions and ways of implementation of Law 10639/03 and the National Curriculum Guidelines for the Education of Ethnic-racial Relations in the context of the quilombola schools, through the understanding of how the local culture, to be used as an interdisciplinary educational resource, can contribute to the construction of identity of children. To this end, a literature review will be carried out having as theoretical assumptions, the studies on the maroon and ethnic-racial education, as well as those related to the role of culture as identity construction tool and achievement of citizenship. Hopefully, with this discussion, to promote reflections on the quilombos and their importance for Brazilian society and to promote new opportunities for educational work in these spaces.

\section{KEYWORDS}

Quilombola Education. Curriculum. Interdisciplinary Methodologies.

\section{RESUMEN}

Este artículo tiene como objetivo tratar sobre los caminos para la efectiva aplicación de la Ley 10.639/03 y de las "Diretrizes Curriculares Nacionais para a Educação das Relações Étnicorraciais" en el ámbito de las escuelas de quilombos en Brasil. Teniendo como hipótesis que la cultura local puede ser utilizada como recurso pedagógico interdisciplinario y como forma de contribuir en la construcción de las identidades de los niños. Por lo tanto, será realizada una revisión bibliográfica sobre la educación quilombola y la educación étnico-racial, como también aquellos referentes al papel de la cultura como instrumento de construcción de identidad y conquista de la ciudadanía. El propósito es empezar una reflexión sobre las comunidades que se originaron de quilombos y de su importancia para la sociedad brasileña, además de fomentar nuevas posibilidades de trabajo pedagógico en esos espacios.

\section{PALABRAS CLAVE}

Educación quilombola. Currículo. Metodologías Interdisciplinarias. 


\section{INTRODUCÇÃO}

A Lei 10.639/03, que estabelece a obrigatoriedade do ensino da história e cultura afrobrasileira e africana em todo o sistema de educação básica, cria novas demandas no campo educacional brasileiro, no que se refere à discussão da participação da população afrodescendente na construção da história e cultura do país.

Mais do que propor um simples estudo da história do Brasil, essa determinação legal tem como finalidade induzir uma releitura dessa mesma história, a partir da ressignificação de fatos e valores, sobretudo em relação ao papel de negros e negras, expatriados e escravizados pelo colonizador português e destituídos totalmente de quaisquer direitos sociais, culturais e econômicos.

No entanto, tais conteúdos têm sido renunciados ou abordados de forma inadequada e folclorizada, por sua imensa carga de equívocos conceituais, em grande parte das escolas, sobretudo em datas como o dia 13 de maio (Abolição da Escravatura) e o dia 20 de novembro (dedicado à Consciência Negra). Para Gomes (2005) a escola carece de princípios éticos que orientem a prática pedagógica e sua relação com a questão racial na escola e na sala de aula.

0 racismo aflora de numerosas formas no sistema educacional, de maneira consciente ou oculta. Assim, por exemplo, podem ser detectadas manifestações de racismo nos livros texto de ciências sociais, história, geografia, literatura, etc.; especialmente por meio dos silêncios com relação a direitos e características de comunidades, etnias e povos minoritários e sem poder. (TORRES SANTOMÉ, 1998, p. 137).

Nessa perspectiva, a criação da Lei 10.639/03 oportuniza a discussão sistemática e interdisciplinar dessa temática, o que pode favorecer uma maior visibilidade do negro e, por conseguinte, uma abordagem mais justa acerca de seu papel na construção do país.
Todavia, é lamentável perceber que, mesmo havendo a obrigatoriedade, as questões étnico-raciais ainda são tratadas com descaso e receio.

Tal situação deve-se, principalmente, ao mito da democracia racial, que é, segundo Santos (2005, p. 14), uma “distorção criada no mundo colonial, como contraparte à inclusão de mestiços no núcleo legal das 'grandes famílias', ou seja, como reação a mecanismos efetivos de ascensão social do 'mulato", que sustenta o discurso de uma suposta igualdade entre as etnias, o que torna desnecessária uma atuação mais militante em busca de direitos civis por parte dos mais excluídos, ou seja, de negros e indígenas.

Nesse contexto, não é surpreendente perceber o despreparo de muitos educadores e educadoras para lidar com a temática racial, seja por não se sentirem preparados, devido à falta de oportunidade ou, na maioria dos casos, à resistência.

Essa discussão, aqui delimitada no âmbito das escolas baianas de educação infantil localizadas em comunidades remanescentes de quilombos e/ou que atendem alunos oriundos dessas, tem como finalidade buscar caminhos para o cumprimento das determinações legais contidas na Lei 10.639/03, assim como na inclusão das comunidades do campo, no que tange ao acesso ao ensino de qualidade, a partir da discussão interdisciplinar e contextualizada da realidade vivenciada em cada território e ampliada para a construção dos conhecimentos produzidos historicamente pela humanidade.

\section{QUILOMBO COMOESPAÇODEESCOLARIZAÇÃO E IDENTIDADE}

A discussão sobre quilombos e seus moradores ainda é muito incipiente em nosso país, sobretudo 
pela difusão da ideia, durante séculos, de que tais comunidades consistiam em grupamentos criminosos (SCHIMITT ET AL., 2002). Ampliando essa perspectiva teórica do conceito de quilombo, as mesmas autoras enfatizam os aspectos de identidade e território que definem os sujeitos descendentes dessas populações e que permanecem habitando tais localidades. Para elas, a expressão remanescente de quilombos indica "a situação presente dos segmentos negros em diferentes regiões e contextos e éutilizada para designar um legado, uma herança cultural e material que the confere umareferência presencial no sentimento de ser e pertencer a um lugar específico" (SCHIMITT ET AL., 2002, p. 01).

Recentemente, o Decreto Federal $n^{0} 4.887$, de 20 de novembro de 2003, regulamenta o procedimento para identificação, reconhecimento, delimitação, demarcação e titulação das terras ocupadas por remanescentes das comunidades quilombolas tendo como principal pressuposto os aspectos relacionados à cultura e à identidade dos moradores. Nessa determinação, quilombos são "grupos étnico-raciais, segundo critérios de auto atribuição, com trajetória histórica própria, dotados de relações territoriais específicas, com presunção de ancestralidade negra relacionada com a resistência à opressão histórica sofrida” (BRASIL, 2003).

Nesse ínterim, é possível perceber, claramente, a importância da identidade e da cultura no processo de resistência e luta por liberdade, assumido e realizado por negros e negras no Brasil escravocrata, sobretudo porque as ideias e teorias difundidas sobre a inferioridade da raça negra em relação à branca favoreceram a manutenção e a expansão do tráfico de negros, no período, e, na posterioridade, serviram (e ainda servem) como alicerce para a difusão de ideologias racistas que perpetuam a opressão dessas populações em relação ao modelo dominante, eurocêntrico.

0 resgate da memória coletiva e da história da comunidade negra não interessa apenas aos alunos de ascendência negra. Interessa também aos alunos de outras ascendências étnicas, principalmente branca, pois ao receber uma educação envenenada pelos preconceitos, eles também tiveram suas estruturas psíquicas afetadas. Além disso, essa memória não pertence somente aos negros. Ela pertence a todos, tendo em vista que os segmentos étnicos que, apesar das condições desiguais nas quais se desenvolvem, contribuíram cada um de seu modo na formação da riqueza econômica e social e da identidade nacional. (MUNANGA, 2008, p. 12).

A educação, na Constituição Brasileira, é determinada como um dever do Estado e direito de todo cidadão, e deverá ser "promovida e incentivada com a colaboração da sociedade, visando ao pleno desenvolvimento da pessoa, seu preparo para o exercício da cidadania e sua qualificação para o trabalho" (BRASIL, 1988, Art. 205). Dessa forma, todo cidadão e toda cidadã, seja ele ou ela criança, jovem, adulto ou idoso, tem direito a esse serviço, sendo, de preferência, uma educação pública e de qualidade.

No entanto, em se tratando da educação oferecida aos alunos das zonas rurais, essa realidade está muito distante de ser alcançada, uma vez que essa modalidade, no Brasil, sempre foi relegada, por motivos ideológicos fundamentados no ideário da elite oligárquica e latifundiária, que sempre cultivou e difundiu a ideia que o estudo não é necessário à gente do campo (LEITE, 2002).

As comunidades remanescentes de quilombos, localizadas, em sua grande maioria, em zonas rurais com maior dificuldade de acesso aos moradores de zona urbana e, portanto, mais excluídas dos serviços essenciais, são caracterizadas pela forte tradição cultural de origem africana, o que as torna especialmente segregadas, por consequência do racismo instaurado e praticado em nosso país, desde o período de colonização.

Nesse sentido, e pensando no processo de escolarização inicial, pode-se afirmar que os estudantes rurais de origem quilombola têm mais probabilidade de apresentar uma maior dificuldade de adaptação a esse modelo, pois, de acordo Nunes (2006, p. 151), nessas localidades, "a oralidade, secularmente, constitui a forma 
de estar no mundo para um grupo étnico que tão pouco acesso teve às chamadas 'letras', à educação formal”.

É importante ressaltar que, nessa perspectiva, o material didático-pedagógico constitui importante instrumento de reprodução de desigualdades, pois apresenta-se totalmente descontextualizado da cultura do campo, ainda mais nas comunidades negras, nas quais o racismo acaba por ser reforçado, pois nos textos e figuras

\begin{abstract}
[...] estereótipos e preconceitos são encontrados; e um dos mais evidente, é aquele que eles denominam de animalização do negro, que é exposta de várias maneiras, sendo a mais comum a associação da cor preta a animais (o porco preto, a cabra preta, o macaco preto) ou seres sobrenaturais animalizados (mula-sem-cabeça, lobisomem, saci-pererê). (SANT’ANA, 2008, p. 53).
\end{abstract}

Com o passar do tempo, essas dificuldades tendem a se ampliar, já que o ensino se dá, muitas vezes, pela leitura de textos mutilados, contidos nos livros didáticos e desvinculados da realidade socioeconômica e cultural destes educandos, submetidos à ação de um currículo escolar urbanocêntrico e que desconsidera a zona rural como espaço de vida e de constituição de cidadania.

\section{O CURRÍ́CULO COMO INSTRUMENTO DE CIDADANIA EM COMUNIDADES QUILOMBOLAS}

A educação quilombola concebida aqui como a efetivação da consideração das especificidades dos quilombolas no tocante "à região, à cultura, à religião que os diferenciam entre si e que precisam ser consideradas na formulação das propostas educacionais (SILVA, 2010), constitui-se numa tentativa de resgate e valorização da cultura e da história dessas comunidades, no âmbito das escolas que se localizam em seu seio ou daquelas que atendem os seus moradores.

Nesse sentido, há que se refletir um pouco acerca da escola e de seu papel na sociedade, principalmen- te no tocante ao modo como ela se posiciona, enquanto instituição, perante a comunidade a que serve.

Barbosa (2007, p. 1062), ao refletir sobre as diferenças existentes entre a cultura escolar e a cultura familiar, afirma que "as lógicas escolares de socialização são distintas e até opostas às culturas e às lógicas de socialização das famílias e das culturas infantis". Com isso, podemos perceber, claramente, que, no processo de realização do seu papel educativo, a escola cumpre a função de "aparelho ideológico do Estado” (ALTHUSSER APUD SILVA, 1999, p. 31), que, num contexto capitalista, pretende moldar os sujeitos e submetê-los à lógica político-econômica vigente.

Nesse sentido, ao pensar na escola situada em comunidades tradicionais negras, vemos que sua estrutura, seu currículo e o material didático disponível acabam por excluir os alunos, pois não valorizam nem aceitam sua cultura e seus saberes. Do mesmo modo, a discriminação e o racismo acabam por serem germinados, por meio da inclusão de mensagens subliminares, veiculadas em termos e imagens pejorativos e depreciativos.

\begin{abstract}
Discutir uma concepção de conhecimento para quilombolas significa pensar em uma formação curricular onde o saber instituído e o saber vivido estejam contemplando, provocando uma ruptura em um fazer pedagógico em que o currículo é visto enquanto grade, hierarquicamente organizado com conteúdos que perpetuam o poder. (NUNES, 2006, p. 150).
\end{abstract}

Percebe-se, então, a necessidade de um trabalho escolar contextualizado e voltado para o atendimento a estes alunos, assim como a imperatividade de elaboração de material suplementar, inerente à sua realidade, considerando, assim, as características próprias de sujeitos identitários e cuja diferença deva ser reconhecida, uma vez que "a identidade e a diferença estão, pois, em estreita conexão com relações de poder. 0 poder de definir a identidade e de marcar a diferença não pode ser separado das relações mais amplas de poder. A identidade e diferença não são, nunca, inocentes" (SILVA, 2000, p. 81). 
Assim, levar em consideração a cultura da comunidade e da criança que aprende é fundamental na proposição de uma educação cidadã. Pensar na criança como integrante de uma sociedade, que também produz cultura e por ela é influenciada diariamente tona o currículo próximo ao estudante e, por conseguinte, comprometido com a transformação social. No caso das comunidades quilombolas, isso é fundamental, pois "pode auxiliar a não cair em explicações simples e caricaturais sobre a dificuldade de escolarização das crianças" (LAHIRE, 1997; THIN, 2006 APUD BARBOSA, 2007, p. 1062).

Considerar as especificidades de culturas predominantemente orais e historicamente negligenciadas implica, necessariamente, em repensar o currículo e as práticas docentes, normalmente copiados e replicados a partir do modelo urbanocêntrico e rico, a partir de uma lógica cidadã. Para Martins (2007, p. 50) não é possível pensar na conquista da cidadania sem a educação, pois "educar, nessa perspectiva, é entender que direitos humanos e cidadania significam prática de vida em todas as instâncias de convívio social dos indivíduos: na família, na escola, na igreja, no conjunto da sociedade".

Do mesmo modo, pensar em alternativas metodológicas, nas quais o conhecimento local seja o ponto de partida para a construção dos conhecimentos escolares, ampliando-se para a conquista dos conhecimentos universais, sem, no entanto, desrespeitar sua identidade, é entrar num movimento de constante parceria com a comunidade, reverenciando, pois a noção de direitos humanos básicos, assim como de tolerância e solidariedade mútuas (BAUMAN, 2013, p. 38).

Nesse sentido, a abordagem interdisciplinar pode ser uma forma efetiva de repensar a escola e seu papel dentro das comunidades tradicionais, tornando-se, também, um instrumento de conquista de cidadania para seus moradores, pela via da escolarização.

\section{CONSIDERAÇÕES FINAIS}

Ações afirmativas são, atualmente, uma importante via de conquista de cidadania para comunidades vítimas de racismo, no Brasil.

Frutos da atuação do movimento negro e das instituições organizadas no seio da sociedade civil em prol dos direitos humanos têm, nesse ínterim, logrado importantes conquistas que têm possibilitado o protagonismo de populações historicamente excluídas e vítimas de todas as formas de violência.

A Lei 10639/03, nesse sentido, atua como um instrumento de formação, pois sua função educativa remete a uma quebra de paradigmas, tais como o mito da democracia racial e os estereótipos que vitimizam negros, indígenas e quilombolas, em longo prazo.

No entanto, a grande penetração de tais ideologias no imaginário coletivo acaba por dificultar o alcance de seu objetivo principal, que é combater o racismo e a intolerância religiosa, pela via da realização da educação escolar, seja pela resistência dos atores pela temática ou sua falta de preparo teórico ou, principalmente, pela concepção da escola como aparelho do Estado.

Nesse sentido, o currículo e práticas educativas reafirmam-se como terreno fértil para a difusão da falaciosa democracia racial, dificultando, pois, a ascensão social e acadêmica de negros, indígenas e quilombolas.

Para combater tal realidade, é necessário que as escolas fundadas e atuantes no seio dessas comunidades, cuja característica principal é a resistência, se fortaleçam para continuar seu papel educador.

Para tanto, é imperioso que a comunidade torne-se parceira dos seus atores, participando da gestão educativa dessas unidades escolares, tanto na construção do currículo quanto na sua realização. 


\section{REFERÊNCIAS}

BARBOSA, M. C. Culturas escolares, culturas de infância e culturas familiares: as socializações e a escolarização no entreter destas culturas. Educação e sociedade, v.2, n.100, Campinas, outubro, 2007. p. 1059-1083.

BAUMAN, Z. A cultura no mundo líquido moderno. Rio de Janeiro: Zahar, 2013.

BRASIL. Constituição Federal. Brasília: Casa Civil, 1988.

BRASIL. Lei 10.639. Brasília: MEC, 2003.

GOMES, N. L. Alguns termos e conceitos presentes no debate sobre relações raciais no Brasil: uma breve discussão. In: Educação anti-racista: caminhos abertos pela Lei Federal n¹0.639/03. Brasília: MEC, 2005.

LEITE, S.C. Escola rural: urbanização e políticas educacionais. São Paulo: Cortez, 2002.

MARTINS, R. Educação para a cidadania: o projeto político pedagógico como elemento articulador. In: VEIGA, I. RESENDE, L. (Org.). Escola: espaço do projeto político-pedagógico. 11.ed. Campinas: Papirus, 2007.

\section{MUNANGA, K. (Org.). Superando o racismo na} escola. Brasília: Ministério da Educação, Secretaria de Educação Continuada, 2008.
NUNES, G. H. Educação Quilombola. In: Orientações e ações para a educação das relações étnico-raciais. Brasília: SECAD, 2006.

SANT’ANA, A. O. História e conceitos básicos sobre o racismo e seus derivados. In: MUNANGA, K. (Org.). Superando o racismo na escola. Brasília: MEC/ SECAD, 2008. p.39-67.

SANTOS, J. 0 poder da cultura e a cultura no poder: a disputa simbólica da herança cultural negra no Brasil. Salvador: EDUFBA, 2005.

SCHMITT, A.; TURATTI, M. C. e CARVALHO, M. C. A atualização do conceito de quilombo: identidade e território nas definições teóricas. Ambiente \& Sociedade - Ano V, n.10, $1^{0}$ semestre de 2002.

SILVA, D. J. Educação quilombola: um direito a ser efetivado. Olinda: Centro de Cultura Luiz Freire; Instituto Sumaúma, 2010.

SILVA, T. T. Documentos de identidade: uma introdução às teorias do currículo. Belo Horizonte: Autêntica, 1999.

SILVA, T. T. (Org). Identidade e diferença - a perspectiva dos estudos culturais. Petrópolis: Vozes, 2000.

TORRES SANTOMÉ, J. Globalização e interdisciplinaridade: o currículo integrado. Porto Alegre: Artes Médicas, 1998. 
